\begin{tabular}{llllll} 
O P E R A T I O N S R E S E A R C H A N D D E C I S I O N S \\
\hline No.3
\end{tabular}

DOI: $10.37190 /$ ord 210307

\title{
PREDICTION OF PORK MEAT PRICES BY SELECTED METHODS AS AN ELEMENT SUPPORTING THE DECISION-MAKING PROCESS
}

\author{
MONIKA ZIELIŃSKA-SITKIEWICZ*, MARIOLA CHRZANOWSKA \\ Department of Econometrics and Statistics, Warsaw University of Life Sciences - SGGW, \\ ul. Nowoursynowska 166, 02-787 Warsaw, Poland
}

\begin{abstract}
Forecasts of economic processes can be determined using various methods, and each of them has its own characteristics and is based on specific assumptions. In the case of agriculture, forecasting is an essential element of efficient management of the entire farming process. The pork sector is one of the main agricultural sectors in the world. Pork consumption and supply are the highest among all types of meat, and Poland belongs to the group of large producers. The article analyses the price formation of class E pork, expressed in $€$ per $100 \mathrm{~kg}$ of carcass, recorded from May 2004 to December 2019. The data comes from the Agri-food data portal. A creeping trend model with segments of linear trends of various lengths and the methodology of building ARIMA models are used to forecast these prices. The accuracy of forecasts is verified by forecasting ex post and ex ante errors, graphical analysis, and backcasting analysis. The study shows that both methods can be used in the prediction of pork prices.
\end{abstract}

Keywords: agricultural sector, pork prices, forecast, creeping trend, ARIMA models

\section{Introduction}

The production and marketing processes, as well as the organisation of the market of various agricultural sectors are subject to an increasing influence of the laws of supply and demand and the rules of competition. Agriculture has to constantly adapt production to market requirements and face the challenges of the global market. This creates conditions for the adaptation of the methods of analysing the risk of price volatility in the agricultural management process to take further measures to protect or stabilise agricultural income.

Prediction of future economic phenomena is critical for planning and decision-making processes, so forecasting can help in making rational decisions [1]. The quality

*Corresponding author, email address: monika_zielinska_sitkiewicz@sggw.edu.pl Received 30 November 2020, accepted 29 September 2021 
of the forecast determines whether decisions based on the prediction process will allow economic entities to develop. Early information on the price level allows farmers and breeders to properly plan work and purchase, and entities related to the agri-food sector to store and process agricultural production. On a macro scale, it provides the basis for making the right decisions as to the adoption of appropriate regulations for agricultural markets or the shaping of agricultural policy.

The pork sector is one of the main agricultural sectors in the world. The supply and consumption of pork have traditionally been the highest among all types of meat. About one-third of all meat consumed in the world is pork, ahead of beef and chicken ${ }^{1}$. The size of the global pork market was estimated at USD 236112.7 million in 2019 and is expected to reach USD 257874.5 million by $2027^{2}$. A statistical Pole eats almost $40 \mathrm{~kg}$ of pork annually, and about 600,000 farms in Poland are involved in the production of pigs.

The aim of the study is to determine class E pork price forecasts with the use of the following models: creeping trend with constant segments of linear trends equal to 5, 7, 9 and 11 periods and ARIMA, and to assess the accuracy of forecasts based on ex post and ex ante error analysis. This will answer the question which approach allows the achievement of the minimum values of forecast errors and can support the decision-making process in the pork sector. The analysis was based on average monthly prices of class E pork (arithmetic mean prices for the whole week) expressed in $€$ per $100 \mathrm{~kg}$ of carcass (paid to suppliers per animal when delivered to the slaughterhouse, excluding VAT), recorded from May 2004 to December 2019. The data comes from the Agri-food data portal, which collects the prices of the most representative agricultural products reported by EU countries. Grade E (Excellent) pork meat is lean meat with a carcass meat content of $55 \%$ or more, but less than $60 \%$. It is the most popular class of pork in the trade.

\section{Pork sector - selected information}

According to the report from June 2020, the Analysis and Strategy Bureau of the National Centre for Agriculture Support [17], Poland, is the sixth EU manufacturer of pork in terms of livestock and the fourth if we take into account the production volume. The situation on the domestic pork market is strongly dependent on what is happening on the EU market (especially in Germany), as well as on the global market. In Poland, a $9 \%$ decrease in the pig population was recorded in 2019 - the largest in the entire

\footnotetext{
${ }^{1} \mathrm{https}$ ://www.mynewsdesk.com/us/renub-research/pressreleases/global-pork-market-forecast-by-production-import-and-export-renub-research-2992871

${ }^{2} \mathrm{https}: / /$ www.alliedmarketresearch.com/pork-meat-market
} 
community. This was mainly due to the threat posed by the ASF virus. This virus also negatively affected the situation on other EU markets and currently remains one of the main determinants of pork prices.

Looking globally, the worldwide production of pork decreased in 2019 from 337 to 225 million tonnes and the entire EU market recorded a drop in pig population in 2019. In Germany, the number of kept pigs dropped by $3.5 \%$ and in Denmark by $2.5 \%$. In turn, pork prices on the EU market were influenced by the average decline in the number of 13 largest producers by less than $2 \%$.

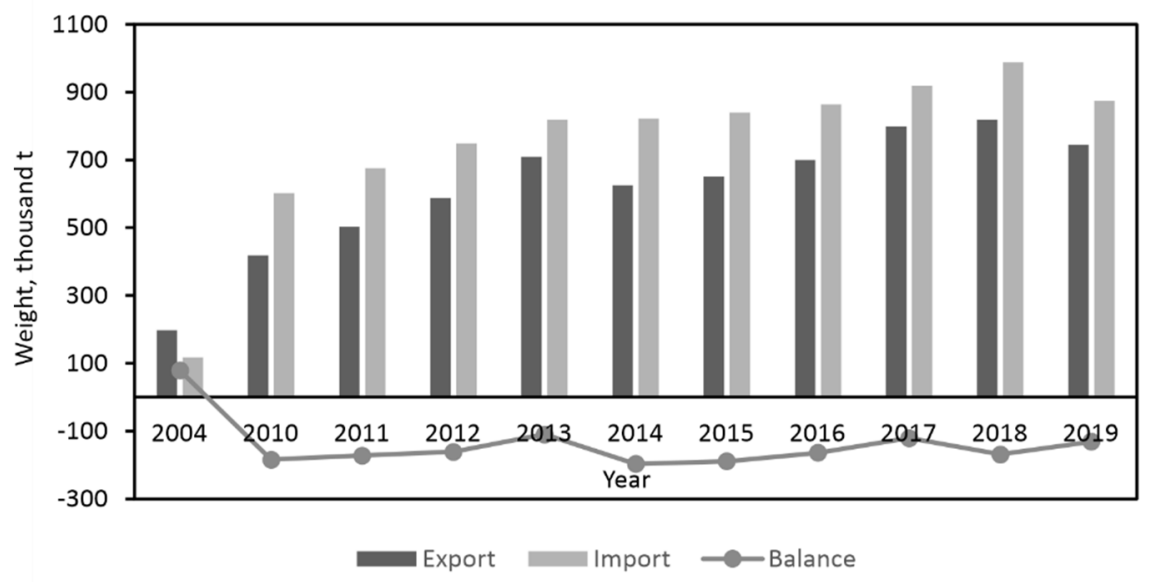

Fig. 1. Export and import of Polish pork in thousands of tons

It should also be noted that Poland has not been able to achieve a positive foreign trade balance in pork products for years (Fig. 1). When it comes to the export of Polish pork, the EU countries are the largest recipients. And it also has a significant impact on pork prices due to relatively lower transport costs. As much as $73 \%$ of domestic exports go to the community market. The most to Germany - about $15 \%$, but it is also Germany that is one of the main pork importers to Poland, apart from Denmark and Belgium. Export volumes do not exceed $10 \%$ to other EU countries (to Italy $9 \%$, to Slovakia and the Czech Republic 6\%, and 5\% to Hungary, the Netherlands and Romania each). The most important non-EU recipient of Polish pork is the United States - 9\% of export, followed by Hong Kong - 5\%, and Vietnam and Ukraine - each 3\%.

When analysing the negative balance in foreign trade, it is worth looking at how competitive the prices of high-quality pork from Polish producers are as compared with the most important producers in the EU. Figure 2 shows the prices of class E pork expressed in $€ / 100 \mathrm{~kg}$ of carcass in Poland and at the largest Polish importers. It can be seen that the relationship between the prices of Polish meat and the prices of port of key EU producers in recent years is not in favour of Polish pork. The main reason was the 
ASF virus and the low competitiveness of pig production, which is a barrier to the development of the industry. The change in export directions for Polish pork took place already in 2014 when, after the first case of ASF was confirmed on the territory of the Republic of Poland, Poland lost the Asian market. The reopening of closed Asian markets is unfortunately still a distant matter. The recent high levels of pork purchase prices were a consequence of the spread of ASF in China which, supplementing its own shortages on the market, began to massively import pork from Europe, and primarily from Germany. Taking into account the significant role that China plays in the global pork trade, any changes in demand in this country are significant for the entire market and determine prices.

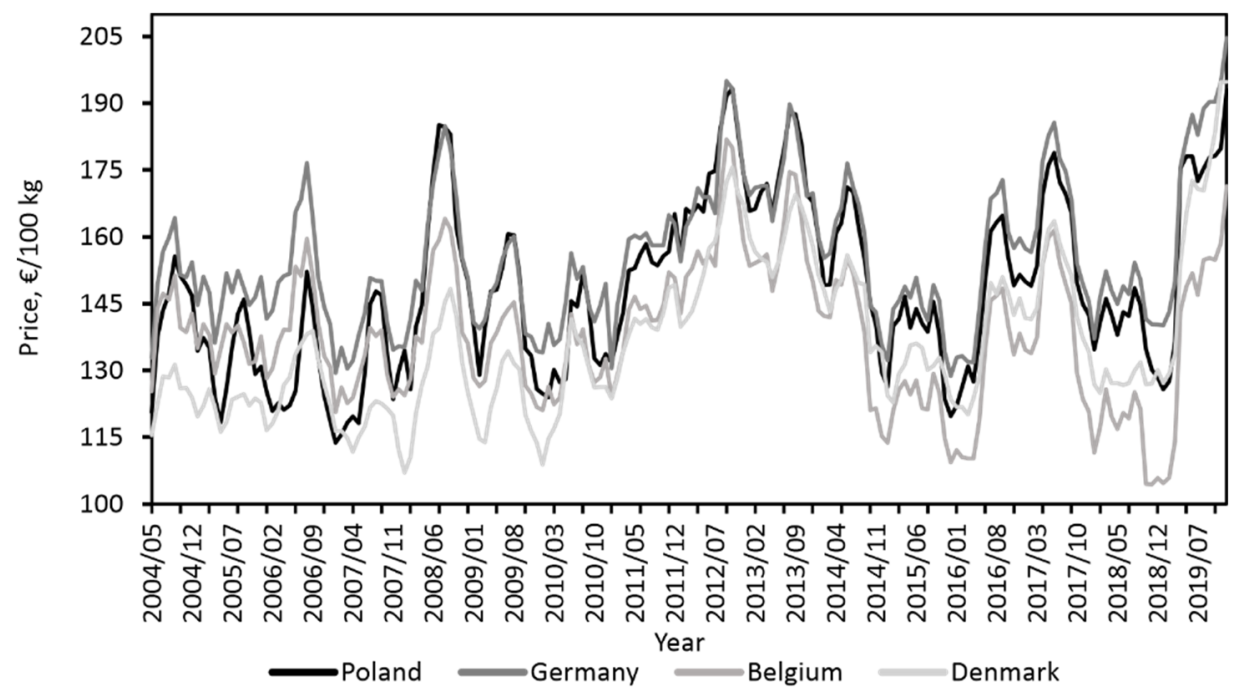

Fig. 2. Prices of Pig meat Excellent $-€ / 100 \mathrm{~kg}$ carcass weight

\section{Determinants of fluctuations in supply, demand, and prices of pork}

In the modern globalised economy, many factors are determining both the increase in pork production and the limitation of its supply. Those that stimulate the production of pork are population growth, rising levels of GDP in developing countries and, consequently, increasing consumer incomes. Determinants limiting the supply of pork are high production costs, transport costs, environmental protection, climate change, declining land acreage for feed production, government interventions, pro-health lifestyle change that entails significant reduction or abandonment of meat consumption and fluctuations in exchange rates currencies, market concentration processes, and many others, including ASF-type diseases. 
This magnitude of factors shapes the situation on the global pork market and affects the fluctuation of pork prices. The observed long-term price volatility on the pork market is also related to so-called swine cycle.

It is one of the types of cyclical fluctuations in agriculture better described in the literature, as researchers have been analysing the economic fluctuations of the pork market since the end of the 19th century. One theory that is still considered a good theoretical explanation of this phenomenon today is the cobweb theorem published in 1938 by Mordecai Ezekiel. The cobweb model is based on three factors:

- The first is the time delay between the moment of making production decisions and its implementation, i.e., the supply $S_{t}=f\left(P_{t}-1\right)$ is a function of prices from the previous period.

- The second factor is the assumption that agricultural producers make decisions based on current prices or prices from recent periods, i.e., the sold production $Q_{t}$ is a function of outdated prices, and the production obtained in $t$ time $Q_{t}=S_{t}$, i.e., it is sold.

- The third element are market prices resulting from equating the current supply with the current demand $D_{t}$, i.e., the price $P_{t}=f\left(S_{t}=D_{t}\right)$ - is a function equal to the supply $D_{t}$ of demand $S_{t}[8]$.

In Poland, among others, Schmidt and Mandecki [19], Kozłowski [10], Małkowski [11], Hamulczuk [7], Hamulczuk and Stańko [8, 9], Stępień [20, 21] and Zawadzka [24, 25] dealt with the problems of the pig cycle and the issue of forecasting pork prices.

Analysing 12 economies, including Poland, Stępień [21] shows that the supply, demand and prices of pork are characterised by cyclical fluctuations, regularly repeated every 3-4 years, and the amplitude of fluctuations while the coefficient of variation is much higher for pork prices than supply. He states that the "pig cycles" still function, but their mechanism is now much more complicated due to the number of variables that determine fluctuations.

\section{Description of methods}

The study uses two forecasting methods. The first one - the creeping trend model is interesting and useful for the short-term prediction method from a wide range of adaptive models, in other words, models adjusting to the output Y series. The main advantage of the model developed by Hellwig in 1967 is the forecasting of series characterised by high irregularities or trend breaks. This method is based on estimating the trend value in each forecast-defined segment of the series using the adjusted linear trends, and then extrapolating the crawling trend thus obtained using harmonic weights. For a given time series $y_{1}, \ldots, y_{n}$ and the smoothing constant $k<n$ determined by the prognosis, the $n-k+1$ parameters of sectional forms are estimated: 


$$
\left.\hat{y}_{t j}=a_{0 j}+a_{1 j} t, j=1, \ldots, n-k+1, t=j, \ldots, j+k-1\right)
$$

where $k$-smoothing constant is the number of cases for each partial trend, $j$-number of partial trend equation, $\hat{y}_{t j}$-determined smoothed value. For a given $t$ from 2 to $n-1$, there is a set of approximants calculated from the partial trends equations, $a_{0 j}, a_{1 j}$ - estimated values of the partial trends equations.

The creeping trend is computed according to the formula:

$$
\hat{y}_{t}=b_{0 t}+b_{1 t} t
$$

and the following calculation can be used to obtain the estimates:

$$
\begin{aligned}
& b_{0 t}=\frac{1}{m} \sum_{j=j_{0}}^{j_{0}+m-1} a_{0 j} \\
& b_{1 t}=\frac{1}{m} \sum_{j=j_{0}}^{j_{0}+m-1} a_{1 j}
\end{aligned}
$$

where $\hat{y}_{t}-$ determined smoothed value (fitted value) for period $t, b_{0 t}, b_{1 t}$ - estimated values being mean values of estimates of the partial trends equations for $t \in\langle j, j+k-1\rangle$, $m$ - number of the partial trends equations for $t \in\langle j, j+k-1\rangle, j_{0}-$ number of the first partial trend equation for $t \in\langle j, j+k-1\rangle$.

By combining successive points $\left(t, \hat{y}_{t}\right)$, a development trend of the time series is obtained in the segment form, the so-called creeping trend. Let us note that the series of predictions is exactly the same length as the output series of real observations. To make a forecast, an algorithm based on harmonic weights should be used [26] $]^{3}$.

Box and Jenkins [2] developed and popularised the use of autoregressive integrated moving average (ARIMA) models and their extensions in many areas of science. The ARIMA models belong to the class of autoregressive models. They are characterised by the fact that they define the functional relationship between the values of the variable forecast in the period (moment) $t$ and the values of the same variable from the previous periods (moments) $t-1, t-2, \ldots, t-p$ with the accuracy of the random component [26]. In this model, three parameters are distinguished: the autoregressive parameter $(p)$, the order of differencing $(d)$, and the moving average parameter $(q)$. For seasonal data, so-

\footnotetext{
${ }^{3}$ Adaptive models in the research on the prices of agricultural products can be found, among others, in the works of Zielińska-Sitkiewicz [27] and Tłuczak [22].
} 
called seasonal ARIMA model $(p, d, q)(P, D, Q)_{s}$ is used, where $s$ is the number of seasons in the period, $P$ - seasonal autoregressive order, $D$ stands for seasonal differencing, $Q$ denotes seasonal order of the moving average. The form of the ARIMA seasonal model $(p, d, q)(P, D, Q)_{s}$ is as follows:

$$
\left(1-\sum_{i=1}^{p} \varphi_{i} B^{i}\right)\left(1-\sum_{i=1}^{P} \Phi_{i} B^{i s}\right) \nabla_{s}^{D} \nabla^{d} y_{t}=\left(1-\sum_{j=1}^{q} \theta_{j} B^{j}\right)\left(1-\sum_{i=1}^{Q} \Theta_{i} B^{j s}\right) \varepsilon_{t}
$$

where $y_{t}$ - analysed variable, $\mathcal{E}_{t}$ - random component, $B$ - delay operator, defined as $B^{i} y_{t}=y_{t-i}, \nabla$-differencing operator, defined as $\nabla y_{t}=y_{t}-y_{t-1}, \nabla^{d}$ refers to the $d$-fold collection of the first differences of the analysed variable, $\phi_{i}, \Phi_{i}, \theta_{j}, \Theta_{j}$ - parameters such as autoregression, seasonal autoregression, moving average, and seasonal moving average, respectively.

The construction process usually takes place in four stages consisting of identification, estimation, verification, and forecasting [26].

In the first stage, the stationarity of the considered time series is examined. In the case of non-stationarity, in order to stabilise the mean, the differentiation operation should be performed. It consists in a $d$-fold calculation of the differences between adjacent terms of the series. The $d$ parameter is set at a level such that the time series of differences obtained as a result of this operation is stationary. Then, for the stationary series, the Box and Jenkins procedure is used to determine the autocorrelation order and the moving average. For this purpose, the functions of autocorrection (ACF) and partial autocorrelation (PACF) are used. In the seasonal series, the autocorrelogram (ACF) and the partial autocorrelogram (PACF) show high values for the multiple of the seasonal delay [4]. ARIMA models in which the order of the moving average is different from zero and non-linear models. In the second stage, iterative procedures are usually used to estimate the parameters of such models.

In the third step, the estimated model is verified. The rest of the model is the basis of diagnostics. The residuals should have white noise characteristics, so the residual autocorrelation coefficients should not be significantly different from zero. For this purpose, plots of the autocorrelation and partial autocorrelation functions for a series of residues are initially analysed. The visual analysis should be supplemented with the Box-Pierce and Ljung-Box tests. If the empirical value of the statistics exceeds the critical value $\chi^{2}$ for the significance level $\alpha$ with $k-p-q$ degrees of freedom (if the model is constant, then with $k-p-q-1$ degrees of freedom), it means that at least one residual autocorrelation coefficient is statistically different from zero [6]. The model under consideration should then be rejected. The verification of the model should also include the examination of the significance of the model parameters. If the model is not verified positively, go back to the first stage and perform the identification again. A positively 
verified model is used to prepare the forecast. Moreover, there is always a necessity to substantive and logical verification of the obtained predictions.

ARIMA models in the application of agricultural product price research can be found in the works of, among others, Dudek [5] for poultry meat prices estimation, Hamulczuk [7] for pork prices prediction, Thuczak and Szewczyk [23] for the study of wheat, rye, beef, and pork prices, Oliveira et al. [12] for the analysis of peanuts, sugar cane, bananas, and oranges prices, Paul et al. [13] for the study of monthly price data of meat and its products, Sangsefidi et al. [18] for prediction of the weekly prices of potato, onion, tomato and veal, Putri et.al. [15] for estimation domestic and international beef prices.

\section{Results}

The directions of changes in the prices of class E pork in the years 2004-2019 in Poland were characterised by an upward trend, around which there were approximately 4-year cyclical fluctuations, in a way confirming the functioning of the "pig cycles" (Fig. 3). Basic information on their features, i.e., the length and amplitude of price fluctuations, is presented in Table 1.

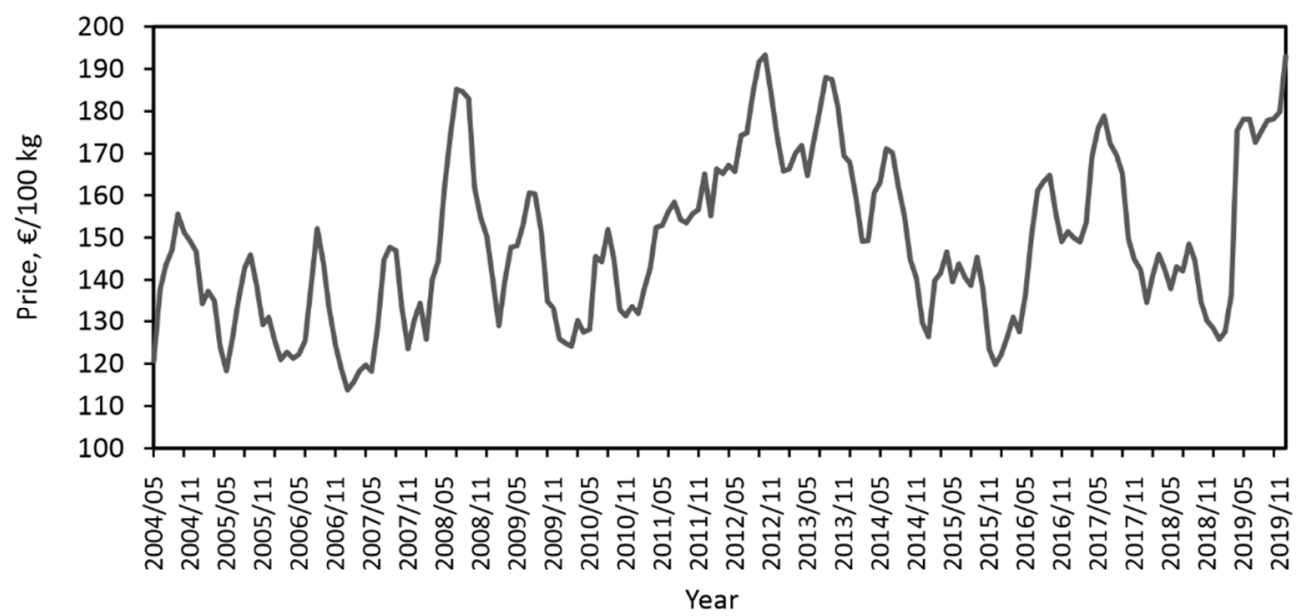

Fig. 3. Prices of pigmeat excellent ( $€ / 100 \mathrm{~kg}$ carcass weight)

The rate of changes in class E pork prices in the analysed time horizon was slightly differentiated in subsequent years, and the average price growth rate was $1.6 \%$ per year. There were also seasonal fluctuations. The highest prices were recorded in the summer periods (June-September), and the lowest at the turn of the years, although the current 
data breaks out this pattern, because in December 2019 there was an increase in the price of pork due to the decline in the stock.

Table 1. Class E pork price cycles in 2004-2019

\begin{tabular}{|c|c|c|c|c|c|}
\hline \multirow[b]{2}{*}{$\begin{array}{c}\text { Cycle period } \\
\text { [year] }\end{array}$} & \multicolumn{2}{|c|}{ Upward phase } & \multicolumn{2}{|c|}{ Downward phase } & \multirow[b]{2}{*}{$\begin{array}{l}\text { Cycle length } \\
\text { [month] }\end{array}$} \\
\hline & $\begin{array}{l}\text { Number } \\
\text { of months }\end{array}$ & $\begin{array}{c}\text { Price increase } \\
\text { index } \\
{[\%]}\end{array}$ & $\begin{array}{l}\text { Number } \\
\text { of months }\end{array}$ & $\begin{array}{c}\text { Price decrease } \\
\text { index } \\
{[\%]} \\
\end{array}$ & \\
\hline $2004-2008$ & 27 & 5.43 & 22 & -4.70 & 49 \\
\hline $2008-2012$ & 26 & 3.98 & 25 & $-3,61$ & 51 \\
\hline $2012-2017$ & 28 & 3.89 & 28 & -4.03 & 56 \\
\hline 2017-? & 14 & 4.93 & 17 & -3.80 & 31 \\
\hline
\end{tabular}

To check the usefulness of the creeping trend models and ARIMA for predicting the price of class E pork, their accuracy was tested by preparing expired forecasts for 2004-2019 and forecasts for the first three months of 2020. The analysis of ex post and ex ante errors was used to verify the obtained predictions and to determine the acceptability of the forecasts. The comparison of the forecasted values with the actual ones gave the basis for formulating conclusions as to the usefulness of the creeping trend model with constant segments of linear trends (5, 7, 9 and 11 periods) and ARIMA models in decision-making processes on the agricultural market in the pork sector. Moreover, it made it possible to determine the scale of the error between the forecasts and the actual state.

Analyses of expired forecast errors for the creeping trend models indicate a slight bias of forecasts towards overestimation and prove the acceptability and accuracy of the determined predictions. MAPE error values are below 5\% (Table 2).

Table 2. Values of the different forecast accuracy measures - a creeping trend

\begin{tabular}{|l|c|c|c|c|}
\hline \multicolumn{1}{|c|}{ Forecast model } & ME & RMSE & MAE & MAPE [\%] \\
\hline Creeping trend model (for $k=5$ ) & -0.0303 & 2.9068 & 2.3190 & 1.5964 \\
\hline Creeping trend model (for $k=7$ ) & -0.0440 & 4.1478 & 3.2832 & 2.2481 \\
\hline Creeping trend model (for $k=9$ ) & -0.0797 & 5.5896 & 4.5286 & 3.0861 \\
\hline Creeping trend model (for $k=11$ ) & -0.0977 & 7.2346 & 5.9563 & 4.0626 \\
\hline
\end{tabular}

Table 3. Values of Theil's forecast accuracy coefficients Theil's U, bias proportion (UM), regression proportion (UR), disturbance proportion (UD)

\begin{tabular}{|l|c|c|c|c|}
\hline \multicolumn{1}{|c|}{ Forecast model } & Theil's U & UM & UR & UD \\
\hline Creeping trend model (for $k=5$ ) & 0.0194 & 0.0001 & 0.0501 & 0.9498 \\
\hline Creeping trend model (for $k=7$ ) & 0.0277 & 0.0001 & 0.1005 & 0.8994 \\
\hline Creeping trend model (for $k=9$ ) & 0.0373 & 0.0002 & 0.1404 & 0.8594 \\
\hline Creeping trend model (for $k=11$ ) & 0.0483 & 0.0001 & 0.1415 & 0.8583 \\
\hline
\end{tabular}


The levels of the Theil coefficients also show that this model reacts quite poorly to the turning points of fluctuations in pork prices (Table 3).
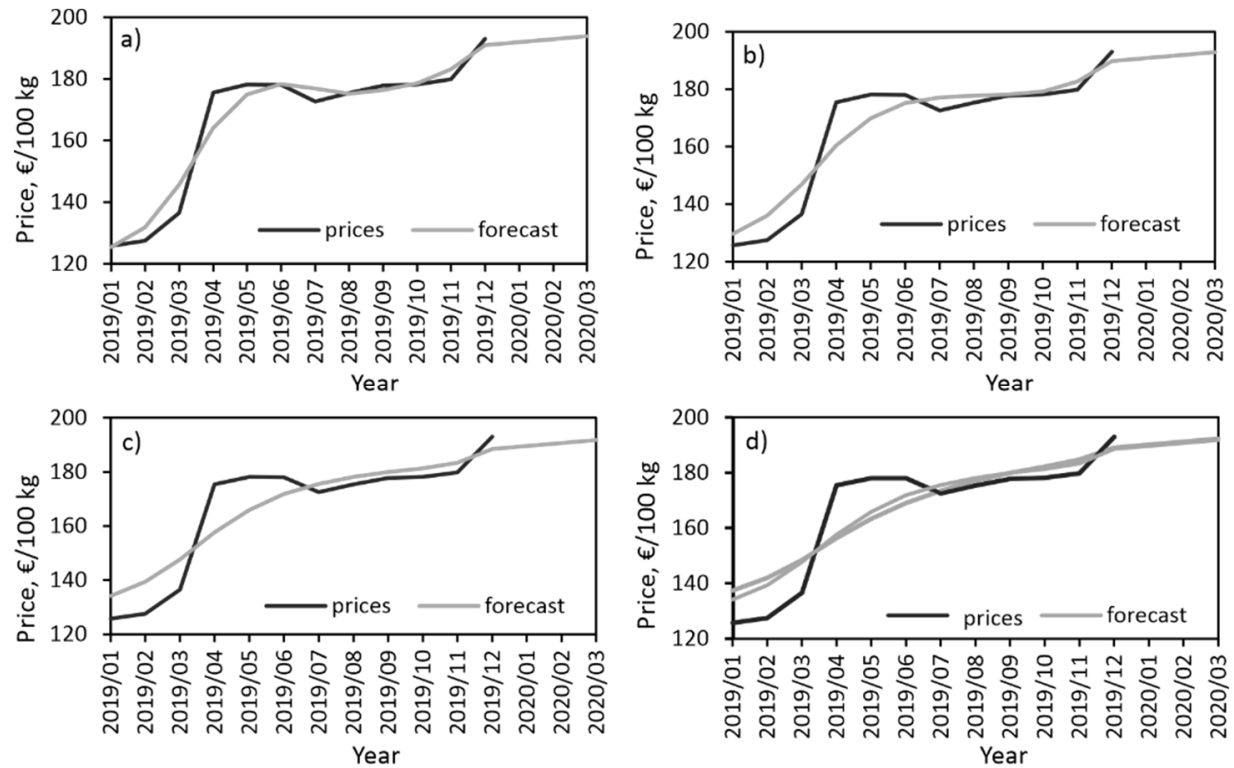

Fig. 4. Prices and forecasts of pigmeat excellent ( $€ / 100 \mathrm{~kg}$ carcass weight); creeping trend model for a) $k=5, \mathrm{~b}) k=7$, c) $k=9, k=11$

As based on the creeping trend models, forecasts for the first quarter of 2020 were also determined (Fig. 4) and satisfactory ex ante error levels were obtained, indicating the acceptability of the obtained predictions (Table 4). The levels of relative forecast errors did not exceed $10 \%$.

Table 4. Values of ex ante mean error $\left(S_{D_{T}}\right)$ and ex ante relative error $\left(\hat{V}_{D_{T}}\right)$ - creeping trend

\begin{tabular}{|l|c|c|c|c|c|c|}
\hline \multirow{2}{*}{ Forecast model } & \multicolumn{2}{|c|}{ January 2020 } & \multicolumn{2}{c|}{ February 2020 } & \multicolumn{2}{c|}{ March 2020 } \\
\cline { 2 - 7 } & $S_{D_{T}}$ & $\begin{array}{c}\hat{V}_{D_{T}} \\
{[\%]}\end{array}$ & $\begin{array}{c}S_{D_{T}} \\
\hat{V}_{D_{T}} \\
{[\%]}\end{array}$ & $S_{D_{T}}$ & $\begin{array}{c}\hat{V}_{D_{T}} \\
{[\%]}\end{array}$ \\
\hline Creeping trend model (for $k=5$ ) & 5.387 & 2.807 & 8.345 & 4.327 & 11.719 & 6.046 \\
\hline Creeping trend model (for $k=7$ ) & 6.628 & 3.474 & 9.195 & 4.794 & 12.339 & 6.397 \\
\hline Creeping trend model (for $k=9$ ) & 8.153 & 4.299 & 10.348 & 5.426 & 13.221 & 6.894 \\
\hline Creeping trend model (for $k=11$ ) & 9.725 & 5.115 & 11.628 & 6.081 & 14.244 & $7.406 \%$ \\
\hline
\end{tabular}

The analysis of class $\mathrm{E}$ pork prices indicated that this series may be non-stationary. This is indicated by Fig. 5 presenting the results of the ACF autocorrelation function and the PACF partial autocorrection function. 

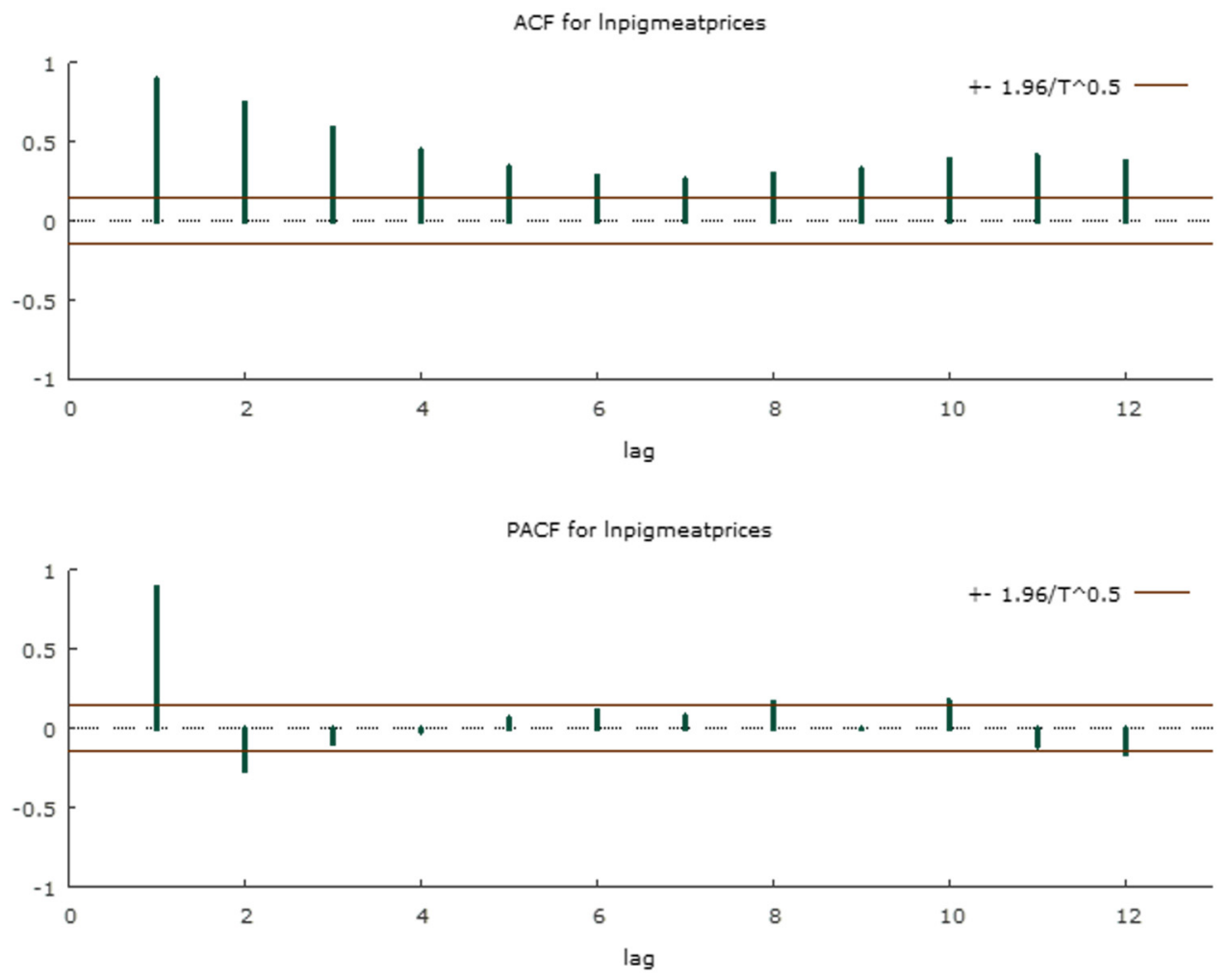

Fig. 5. ACF and PACF functions for variable lnpigmeatprices

The use of the ADF test did not give clear answers to this question. The results depend on the nature of the model and its delays. For example, for a time series of levels with both an intercept and a linear trend, and with a delay of 1, the test showed that the price time series is stationary ( $H_{0}$ of the unit root was rejected). On the other hand, the additional inclusion of seasonal variables did not allow for the rejection of the non-stationarity hypothesis. After a series of trials and the analysis of several models, two were finally selected for analysis: ARIMA $(1,0,1)(0,0,1)$ and ARIMA $(1,0,0)(0,1,1)$. The selection of the models for the study was guided by the statistical significance of the parameters and the properties of the rest of the model. The estimation results of the ARIMA $(1,0,1)(0,0,1)$ and ARIMA $(1,0,0)(0,1,1)$ models are presented in Tables 5 and 6.

The quality of the predictions obtained with the ARIMA $(1,0,1)(0,0,1)$ and ARIMA $(1,0,0)(0,1,1)$ models is high. The obtained errors of expired ex post forecasts are at the levels indicating the acceptability and accuracy of the calculated forecasts (Table 7). 
Table 5. Model 1: Estimation ARIMA $(1,0,1)(0,0,1)$, observations 2004.05-2019:12 ( $N=188)$

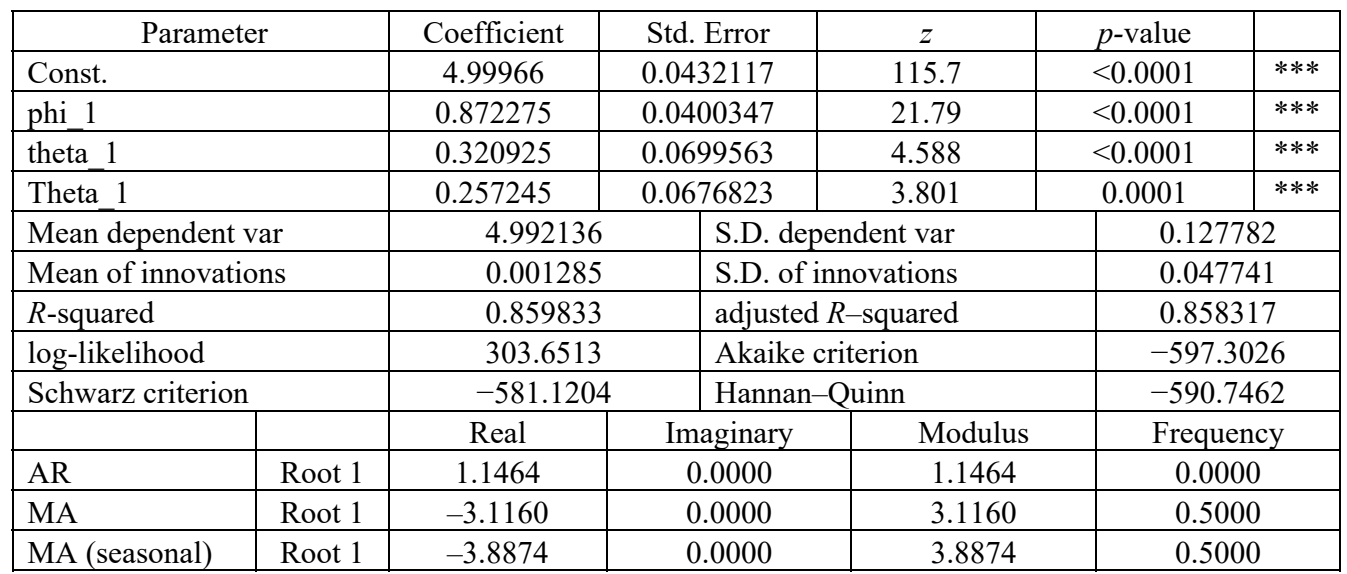

Table 6. Model 2: Estimation ARIMA $(1,0,0)(0,1,1)$, observations 2004.05-2019.12 $(N=188)$

\begin{tabular}{|c|c|c|c|c|c|c|}
\hline \multicolumn{2}{|c|}{ Parameter } & Coefficient & Std. Error & $z$ & $p$-value & \\
\hline \multicolumn{2}{|l|}{ Const. } & 0.0168545 & 0.0105854 & 1.592 & 0.1113 & \\
\hline \multicolumn{2}{|l|}{ phi 1} & 0.905222 & 0.0377217 & 24.00 & $<0.0001$ & $* * *$ \\
\hline \multicolumn{2}{|l|}{ theta 1} & 0.216420 & 0.0756806 & 2.860 & 0.0042 & $* * *$ \\
\hline \multicolumn{2}{|l|}{ Theta 1} & -0.829497 & 0.0690212 & -12.02 & $<0.0001$ & $* * *$ \\
\hline \multicolumn{2}{|c|}{ Mean dependent var } & \multicolumn{3}{|c|}{ S.D. dependent var } & \multicolumn{2}{|c|}{0.137015} \\
\hline \multicolumn{2}{|c|}{ Mean of innovations } & \multicolumn{2}{|c|}{-0.000615} & S.D. of innovations & \multicolumn{2}{|c|}{0.044337} \\
\hline \multicolumn{2}{|c|}{$R$-squared } & \multicolumn{2}{|c|}{0.885417} & Adjusted R-squared & \multicolumn{2}{|c|}{0.884092} \\
\hline \multicolumn{2}{|l|}{ log-likelihood } & \multicolumn{2}{|c|}{290.9274} & Akaike criterion & \multicolumn{2}{|c|}{-571.8549} \\
\hline \multicolumn{2}{|l|}{ Schwarz criterion } & -556.00 & \multicolumn{2}{|c|}{ Hannan-Quinn } & \multicolumn{2}{|c|}{-565.4252} \\
\hline & & Real & Imaginary & Modulus & \multicolumn{2}{|c|}{ Frequency } \\
\hline AR & Root 1 & 1.1047 & 0.0000 & 1.1047 & \multicolumn{2}{|c|}{0.0000} \\
\hline MA & Root 1 & -4.6206 & \multirow{2}{*}{$\begin{array}{l}0.0000 \\
0.0000\end{array}$} & 4.6206 & \multicolumn{2}{|c|}{0.5000} \\
\hline MA (seasonal) & Root 1 & 1.2056 & & 1.2056 & \multicolumn{2}{|c|}{0.0000} \\
\hline
\end{tabular}

Table 7. Values of the different forecast accuracy measures ex post-ARIMA models

\begin{tabular}{|l|c|c|}
\hline \multicolumn{1}{|c|}{ Parameter } & ARIMA $(1,0,1)(0,0,1)$ & ARIMA $(1,0,0)(0,1,1)$ \\
\hline Mean error & 0.0012851 & -0.00061463 \\
\hline Root mean squared error & 0.047741 & 0.044337 \\
\hline Mean absolute error & 0.036922 & 0.034486 \\
\hline Mean percentage error & 0.017124 & -0.01672 \\
\hline Mean absolute percentage error & 0.74022 & 0.68999 \\
\hline Theil's U & 0.8834 & 0.83055 \\
\hline Bias proportion, UM & 0.00072461 & 0.00019217 \\
\hline Regression proportion, UR & 0.00047814 & 0.022214 \\
\hline Disturbance proportion, UD & 0.9988 & 0.97759 \\
\hline
\end{tabular}



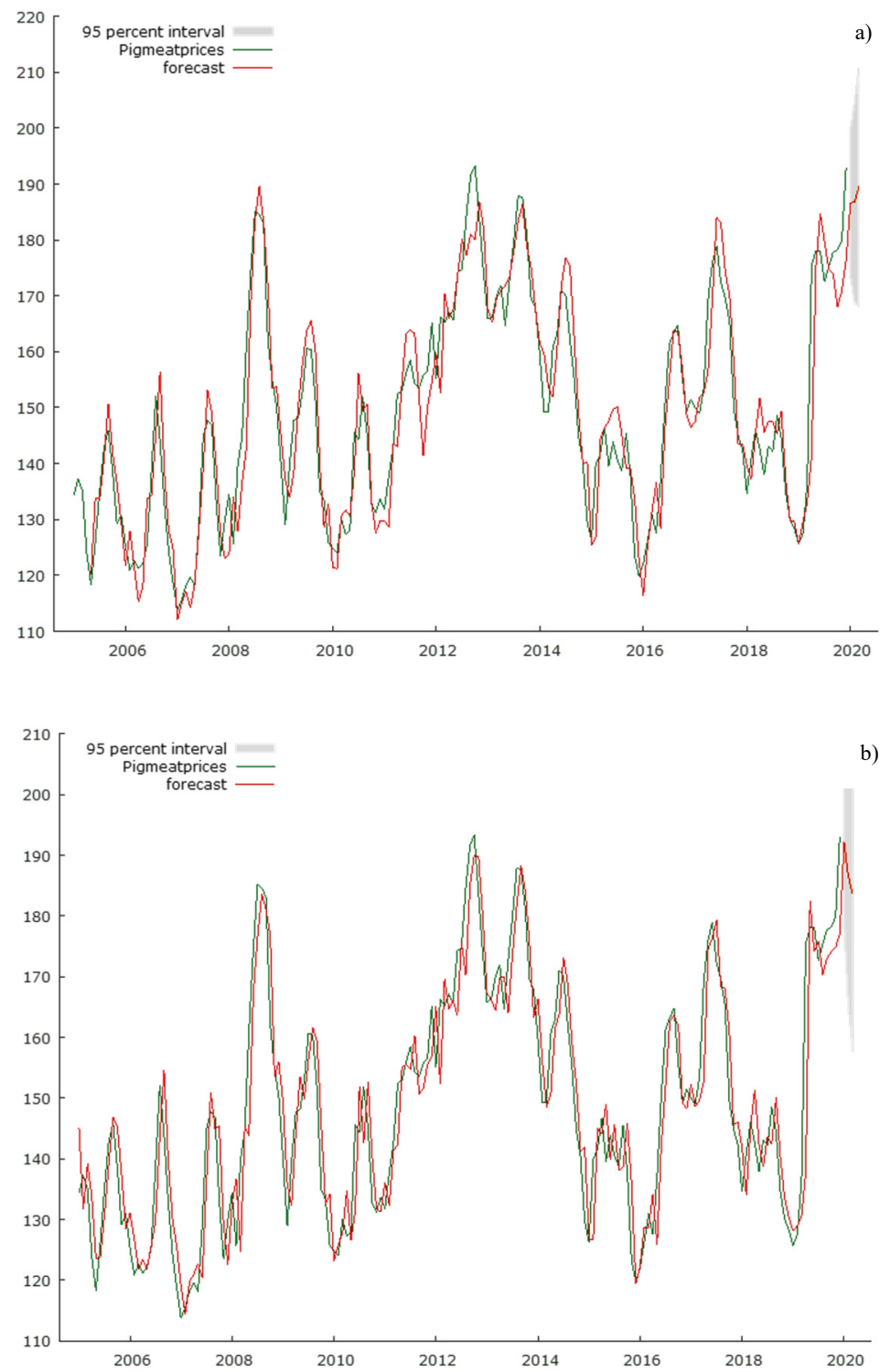

Fig. 6. Prices and forecasts of pigmeat excellent ( $€ / 100 \mathrm{~kg}$ carcass weight $)$ - ARIMA: a) model $(1,0,1)(0,0,1)$, b) model $(1,0,0)(0,1,1)$

It can be noticed that the ex post forecasts calculated based on the model $(1,0,1)$ $(0,0,1)$ allowed the correct assessment of the situation in a longer period. The forecasts estimated based on the model $(1,0,0)(0,1,1)$ turned out to be closer to reality in short-term forecasting. When analysing Fig. 6 , it can be noticed that the forecasts estimated 
from models based on undifferentiated data show better prognostic abilities in the longer term. For forecasts built based on models taking into account differentiated data, greater efficiency is observed over a period of several months. This means that the differentiation causes a disturbance of long-term relationships [3].

The calculated ex ante forecasts with the model $(1,0,1)(0,0,1)$ indicated a decrease in pork prices in the first three months of 2020, which was fairly consistent with the market situation. On the other hand, the ex ante predictions obtained by the model $(1,0,0)(0,1,1)$ were closer in terms of value to real prices but suggested a wark upward trend (Fig. 6).

The obtained ex ante forecast errors indicate high prediction accuracy of both ARIMA models. The results of the mean prediction error and relative ex ante error are included in Table 8.

Table 8. Values of ex ante mean error $\left(S_{D_{T}}\right)$ and ex ante relative error $\left(\hat{V}_{D_{T}}\right)$ - ARIMA models

\begin{tabular}{|c|c|c|c|c|c|c|}
\hline \multirow{2}{*}{ Forecast model } & \multicolumn{2}{|c|}{ January 2020} & \multicolumn{2}{c|}{ February 2020} & \multicolumn{2}{c|}{ March 2020} \\
\cline { 2 - 7 } & $S_{D_{T}}$ & $\begin{array}{c}\hat{V}_{D_{T}} \\
{[\%]}\end{array}$ & $S_{D_{T}}$ & $\begin{array}{c}\hat{V}_{D_{T}} \\
{[\%]}\end{array}$ & $S_{D_{T}}$ & $\begin{array}{c}\hat{V}_{D_{T}} \\
{[\%]}\end{array}$ \\
\hline ARIMA $(1,0,1)(0,0,1)$ & 0.047741 & $0.91 \%$ & 0.074325 & $1.43 \%$ & 0.089405 & $1.72 \%$ \\
\hline ARIMA $(1,0,0)(0,1,1)$ & 0.044337 & $0.85 \%$ & 0.066626 & $1.28 \%$ & 0.080409 & $1.53 \%$ \\
\hline
\end{tabular}

\section{Conclusions}

Summarising the research results for forecasts determined with the use of the creeping trend, the lowest values of the average relative errors of ex post and ex ante forecasts were obtained for the model with the shortest segments. Forecast errors increased, depending on the increase in the value of the smoothing parameter $k$. These results can be explained by the variability of the examined phenomenon, which was characterised by high irregularity and trend breakdown.

On the other hand, the quality of the predictions obtained with ARIMA models is satisfactory. The errors of expired ex post forecasts are below $4 \%$ for pork prices and below $1 \%$ for logarithmic prices. On the other hand, the relative errors of ex ante predictions for the analysed forecast horizon do not exceed $2 \%$.

The results of Theil's coefficients indicate that both in the case of the creeping trend models and ARIMA models, the forecast errors result from disturbance proportion of turning points.

The presented research results should not be treated arbitrarily, because in the case of time series with a different course, with observed cycles, trend breaks and random fluctuations, better results could be obtained using other methods. The effects of using 
the creeping trend model are satisfactory only for short-term forecasts. This model can also be used to predict other phenomena and processes.

ARIMA models are used in short-term forecasting for differentiated data and in long-term forecasting for data without differentiation. They are an effective tool in predicting the prices of agricultural products.

The tested time series models allow for drawing conclusions regarding the correctness of pork price formation and can be an effective tool for forecasting and supporting the decision-making process. The problem of using ARIMA models in forecasting pork meat prices presented in this paper is a prelude to further in-depth analysis of the use of ARIMA and SARIMA models in modeling agricultural prices.

\section{References}

[1] ARmstrong J.S., Principles of Forecasting: A Handbook for Researchers and Practitioners, Springer, New York 2001.

[2] Box G.E.P., Jenkins G.M., Time series analysis: Forecasting and control, Holden-Day, San Francisco 1970.

[3] Box G.E.P., JENKIns G.M., Time series analysis: Forecasting and control, PWN, Warsaw 1983 (in Polish).

[4] CIEŚLAK M., Economic forecasting. Methods and applications, PWN, Warsaw 2001 (in Polish).

[5] DudeK H., Forecasting of poultry meat prices by using seasonal Arima model, Ann. Polish Association of Agricultural and Agribusiness Economists, 2005, 7 (5), 19-25 (in Polish).

[6] Enders W., Applied Econometric Time Series, 2nd Ed., Wiley Series in Probability and Statistics, Wiley, Hoboken 2004.

[7] HamUlCZuK M., Application of the ARIMA models to the pork prices forecasting, Polish Association of Agricultural and Agribusiness Economists, 2006, 8 (5), 43-47 (in Polish).

[8] Hamulczuk M., StańKo S., Factors affecting changes in the prices and farmers' incomes in the Polish pig market, Probl. Agric. Econ., 2013, 3 (336), 44-66 (in Polish).

[9] HamulCZuK M., StańKo S., Forecasting the prices of basic products on the example of wheat and pork livestock, Price risk management and the possibilities of stabilizing the income of agricultural producers - cognitive and application aspects, IAFE-NRI, Warsaw 2009, 181-207 (in Polish).

[10] KozŁowski Z., On the system of economic impact on stabilisation of pigs development, Part I. Modern Countr., 1964, 3 (in Polish).

[11] MAŁKOWSKI J., Efficiency of regulating production and supply of pigs, Cooperative Research Institute, Warsaw 1971 (in Polish).

[12] Oliveira S.C., Pereira L.M.M., Hanashiro J.T.S., Val P.C., A study about the performance of time series models for the analysis of agricultural prices, GEPROS, 2012, 7 (3), 11-27.

[13] Paul R.K., Panwar S., Sarkar S.K., Kumar A., Singh K.N., Farooqi S., Choudhary V.K., Modelling and forecasting of meat exports from India, Agric. Econ. Res. Rev., 2013, 26, 249-255.

[14] Pork Meat Market, https://www.alliedmarketresearch.com/pork-meat-market

[15] Putri R.T., SukiYono K., Sumartono E., Estimation of Indonesian beef price forecasting model, Agritrop. J. Agric. Sci., 2019, 2 (1), 46-56.

[16] Report Global Pork Market Forecast by Production, Import and Export - Renub Research, https:// www.mynewsdesk.com/us/renub-research/pressreleases/global-pork-market-forecast-by-productionimport-and-export-renub-research-2992871 
[17] Information on the situation on the pork, beef and poultry market. Report, Analysis and Strategy Bureau of the National Centre for Agriculture Support in Poland, June 2020 (in Polish).

[18] Sangsefidi S.J., Moghadas R., YAZdani S., NeJAd M., Forecasting the prices of agricultural products in Iran with ARIMA and ARCH models, Int. J. Adv. Appl. Sci., 2015, 2, 54-57.

[19] SCHMidT S., MANDECKI S., Production of pigs in the light of economic research, Economic Society in Kraków, Kraków 1933 (in Polish).

[20] STĘPIEŃ S., Structural changes in the pigmeat sector in selected European Union countries, J. Agribus. Rural, 2014, 1(31), 133-141 (in Polish).

[21] StĘPIEŃ S., Cyclical fluctuations in the market of pork on a global scale, Ann. Polish Association of Agricultural and Agribusiness Economists, 2015, 17 (3), 362-366 (in Polish).

[22] TŁUCZAK A., The effectiveness of adaptive models in forecasting agricultural prices, Scientific Publications of University of Economics in Katowice, Economic situation and functioning of markets, 2009, 123-133 (in Polish).

[23] TŁuCZAK A., SZEWCZYK M., The effectiveness of the autoregressive models in forecasting the agricultural prices in Poland, Oecon. Coper., 2010, 1 (1), 99-119.

[24] ZawadzKa D., The history of research on the "pig cycle”, Probl. Agric. Econ., 2010 (1), $207-217$.

[25] ZAWADZKA D., Functioning of the meat market and the pork cycle, Ph.D. thesis, IAFE-NRI, Warsaw 2014 (in Polish).

[26] Zeliaś A., Pawelek B., Wanat S., Economic Forecasting, PWN, Warsaw 2013 (in Polish).

[27] ZIELIŃSKA-SiTKIEWICZ M., Forecasting prices of broiler chickens using the creeping trend, Proc. 19th International Scientific Conference on Economic Science for Rural Development, Jelgava (Latvia), 2018, 537-546. 